\title{
The Integration of Quality-Oriented Education and Instrument-Driven Training in Chinese College English Teaching
}

\author{
Shi Jian ${ }^{1}$ \\ ${ }^{1}$ College of Humanities and Foreign Languages, Xi' an University of Science and Technology, China \\ Correspondence: Shi Jian, College of Humanities and Foreign Languages, Xi'an University of Science and \\ Technology, Lintong District, Xi'an Shaanxi 710600, China. E-mail: smith168@126.com
}

Received: January 31, 2013 Accepted: March 2, 2013 Online Published: April 3, 2013

doi:10.5539/elt.v6n5p38 URL: http://dx.doi.org/10.5539/elt.v6n5p38

\begin{abstract}
College English Teaching (CET) plays an important and basic part in the whole college education system in China and whether it should adopt the quality-centered education or tool-oriented training remains controversial in current Chinese CET practices. After comparing several basic concepts and analyzing the existing problems in Chinese practical CET, the paper finds that contemporary Chinese CET is largely influenced by pragmatism and utilitarianism and has an obvious instrument-driven tendency. The cultivation of humanistic quality, however, is weakened and even ignored intentionally or unintentionally. And it holds CET should give full play to the advantage of the language as well as conduct subtle humanistic education for students to achieve the integration of tool-oriented and quality-centered goal in CET.
\end{abstract}

Keywords: college English teaching, humanistic quality education, instrumental training, integration

\section{Introduction}

English, as a lingua franca, is an effective and frequently-used tool for people to communicate, to think and to transmit information throughout the global village in these days. Meanwhile, English language inherits, develops and creates the culture of the whole human being because of its great tolerance for change and massive assimilation from other languages and cultures, so it contains abundant and profound humanism. But whether college English education should highlight the instrumental or humanistic aspect in the field of foreign language education, there have been two completely different views. Some hold that overemphasizing tool-oriented training will produce greater harm to CET. English teaching should eradicate the instrumental tendency and strengthen the humanistic essence. Chinese Foreign Language Teaching Committee (CFLTC) decides to change the misconceptions about the characteristics of foreign language education, reckoning that foreign language education is not a tool for training and it should be a basic quality education. Others maintain that establishing the instrumental goal of English teaching is not only to conform to the requirements of education itself, but also to comply with the instruction of English teaching development from basic phrase to higher education. As a matter of fact, comprehensive humanistic quality education is not just the mainstream academic view in the practices of English for General Purpose (EGP), namely, CET; but is the guiding ideology of the teaching of English for Specific Purposes (ESP) as well in the present situations of foreign language teaching English as a foreign language (EFL). So English is deemed as a compulsorily required language course for all majors across varied types of colleges and universities. Theoretically speaking, CET not merely should reflect the characteristics of English serving as a tool, but more importantly should enforce the nurturing of humanistic quality.

Practically, however, highly influenced by social pragmatism and utilitarianism, CET in China presently has an obvious tendency - exam-oriented education, whose dominance is fairly widespread and far-reaching. CET is increasingly inclined to teach students practical language knowledge and useful examination skills to pass various tests for different certificates, gradually ignores the cultivation of all-round person, and completely deviates from the original intention of education as well as the syllabus requirements issued by the Chinese CET Committee. The examination-oriented education is the sole purpose of the college English curriculum; Student-centered teaching concept is comparatively faint, which makes students feel English learning is a huge burden, and they think learning English is just for getting high marks. Even some institutions have a clearly-stated rule that students can not obtain a degree if they fail to arrive at a certain score in college English 
Test Band 4 or 6 (CET4 or 6). So passing CET4, CET6 almost becomes the direct driving force of many students to learn English in college. In the daily routines of teaching and learning college English, the fostering of humanism and spiritual values is weakened or ignored intentionally or unintentionally.

\section{Comparison and Differentiation of Several Basic Concepts}

\subsection{Quality Education vs. Instrument Training}

Language is a tool for exchanging ideas with others, and this characteristic determines the purpose of English teaching, which is to train students to be able to use this instrument to communicate. In terms of tool-oriented training, English teaching assumes the task what is to cultivate students fundamental English literacy and develop their thinking ability. That is to say, students can grasp the basic knowledge of English language and develop the basic skills of listening, speaking, reading, writing and translating through English teaching so that it can let students possess the capability to communicate with others and to promote the development of ideation skills further. In this way they can lay the solid foundation for their continuing to learn English itself and use English to acquire other related scientific and cultural knowledge.

Being one of the three liberal arts, i.e., language, history, and philosophy, English language and its related culture are colorful ,broad and profound, which can promote students' humanistic accomplishment and ideological level. In terms of the cultivation of humanistic quality, English education shoulders the responsibility of nurturing and improving students' humanistic qualities. In other words, students can broaden their horizons, enrich their life experiences through English class to form the cross-cultural awareness, develop the innovation ability, thus cultivating the good character of their own and correct outlook on life and values.

\subsection{English Education vs. English Teaching}

Cook (2007) considers foreign language education has two components: external goals and internal goals. External goal is more direct and practical, such as going abroad, negotiating business, touring in exotic cultures etc.; internal goal is more essential and extensive including training students to have different ways of thinking, to understand different values, to improve personal qualities etc. Therefore, foreign language education does not solely refer to the improvement of simple language skills and ability, but means to incorporate the cultivation of humanistic quality and cultural accomplishment too.

However, quoted from professor Cai Jigang (2010), English teaching gives great priority to much more external goals, which are to train students to grasp a kind of communicative tool or some language skills employed in certain fields. In English class, teachers design diversified teaching activities in order to drill students in hope to enhance their language sense and techniques, without considering the cultural contents and social meanings of the teaching materials.

\section{The Problems in Existing CET}

Under the influence of traditional examination-oriented education, score has always been thought highly of, and students also seem to treat passing the exam as the only goal of teaching college English, especially CET4 \& 6 . Greatly influenced by social pragmatism and utilitarianism, CET takes on an obvious inclination of instrumental training, just as Cheng Zhenquan (2008) concludes: "CET pays much attention to skills but weakens humanistic qualities". Professor Liu Runqing (2004) from Beijing Foreign Studies University also mentions that in the 21 century, the purposes of many English teaching tend to be commercial rather than to develop culture and society, and it strays from the original intention of education. Apart from the fact that most college English teachers make students buried their heads into lots of exercises before the CET4\&6, some school administrations will also hire experienced teachers to do extracurricular tutoring for their students. In addition, there are still some students attending some private training class at great expenses around campus or even to the downtown areas. Owing to these misconceptions and misdeeds we hold, there are some serious problems available in the prevailing CET practices, which are listed as follows:

\subsection{The Lack of Sturdy and Overall Language Skills}

As is known to all, the skills in language learning and acquisition involve listening, speaking, reading, writing, and translating. Larsen-Freeman, the famous American language educationist, proposes that we should also strengthen the grammar skill apart from the commonly mentioned five techniques, namely the ability to grasp grammar.

However, the basic abilities of English are not developed in a comprehensive and balanced way in CET. For one thing, traditionally we always prefer reading and writing to listening and speaking, because we can merely come into contact with some English written materials in the past. But now we have more access and opportunity to 
communicate with people from English-speaking countries face to face with the widening and deepening of the reform and opening policy, English listening and speaking proficiency becomes more and more important and prominent. Many students, who are very skillful at reading and writing, turn into persons incapable of acquiring and conveying information through listening and speaking when they encountered the impromptu communications with foreigners because there exists inadequate audio and oral training in CET class. Recent years has witnessed the increased amount and form of listening test in CET4\&6, which can gear up our CET practice to some degree, but spoken test solely allows those to take whose CET4\&6 score reach a certain standard, so quite a number of college students neglect the spoken English training, not to mention speaking English fluently. For another, students often write some Chinglish because they do not master English grammar completely. Even worse, their writings have no content or no idea, let alone their translating competence in English Chinese mutual translations.

\subsection{The Shortage of Cultural and Humanistic Introduction}

Some people think humanistic education is the responsibility of the humanity curriculums, especially the ideological and political courses; it has nothing to do with the college English courses. In fact, from the discipline classification, as a foreign language course, English belongs to the humanity subjects. When teachers impart language knowledge, they also shoulder the mission of spreading culture.

In our practical CET class, nevertheless, the traditional teacher-centered grammar-translation teaching approach, which is viewed as the more beneficial way to consolidate the language foundation, has been implementing in most areas of China. A large amount of time and efforts are spent on the demonstration of vocabulary, the explanation of grammar, the translation of text and the analysis of structure without taking the theme and cultural connotations of the text into consideration. In this way, students lose the chance to broaden the field of their visions, to enlarge the range of their knowledge, and to deepen their understanding of foreign cultures.

\section{Introducing Quality Education into CET}

\subsection{The Significance of Quality Education in CET}

College English, being a foreign language course, is also a very good humanistic education course, because language is the carrier of culture. Language is not only a communicative tool, but also is a means of expressing thoughts and feelings, exchanging ideas and emotions, and transferring culture and custom. As Cheng Zhenquan (2008) says, College English is an instrumental course, but also is a humanistic course. When teachers instill language knowledge to students, they can also implant humanistic ideas to students. Besides, the College English course, as a kind of humanity education form, English teachers can transfer humanistic information to students effectively because they can make use of their language competence and it is comparatively easy for students to accept what teachers said and taught in the teaching process since language teachers play a vital role in the shaping of the students' personalities. Thereby, English teachers should actively employ their language competence and let the humanity education integrate into the teaching of language knowledge.

In the English teaching, the advantages of humanistic qualities still indicate that teachers and students should always communicate with each other. In college English curriculum, teachers have more opportunity to understand the student's life and to know more about the students' inner worlds when lecturing, which can not be managed in other courses. With the progress of teaching mode, the teacher-centered method is changed gradually into student-oriented one; English teaching also fully embodies the "people-oriented" principle. In class, students can freely express their visions, which is beneficial to close the distance between teachers and students and makes students accept teachers' ideas easily and willingly.

\subsection{How to Conduct Quality Education in CET}

\subsubsection{Introduction before the Class}

At present, most college English textbooks are compiled under the guideline of content-based instruction (CBI) and theme-related arrangement (TRA). The texts in each unit centers around the same theme and their contents are relevant to some extent. Prior to the explanation of the text, teachers can either introduce directly some cultural background and humanistic information to arouse students' interest enormously or assign students some preview tasks to find some data or classics by surfing the internet and consulting the library to enlarge their reading extensively. Thus doing, it can lead students into the unit naturally in a panoramic way, both broadening their views and informing the major ideas.

Let's take the unit "Fighting with the Forces of Nature" for an example, which comes from the College English Integrated Course 4 published by Shanghai Foreign Language Education Press (SFLEP). Before the class, teachers can elicit the text by asking "do you think nature plays an important role in our life?" Then ask the 
students to recall the miserable scene of the low temperature sleet frozen disaster happened in the south part of China in Jan. 2007 and the devastating catastrophe of earthquake occurred in Wenchuan, Sichuan Province in May 2008. Students can easily seek the answer to the above question. Next, teachers can enlighten students to recollect the history about the two notorious invasions in two World Wars and raise them such questions as "In what way was Hitler's offensive against the Soviet Union similar to Napoleon's campaign against Russia? Why both of them failed?" and what does the "icy defender" in the title refer to? Associating with their historical knowledge, students may come to the conclusion that "man proposes God disposes". In doing so, students can generally grasp the theme of the unit: the forces of nature are too powerful to be resisted and man must be careful not to disregard the law of nature. Otherwise you will be taught a painful lesson and punished harshly by nature, whoever you are, just like the two historic figures, Hitler and Napoleon.

\subsubsection{Elaboration during the Class}

When teachers start to interpret the text, they will surely demonstrate some linguistic and grammatical difficult points like the usage of new words, the analysis of complex sentence constructions, the explanation of special grammar phenomena etc.. In addition, they should also disclose some humanistic information closely connected with the text because most of them are highly selected and entirely instructive.

Let's take the unit "There's a Lot More to Life than a Job" as an instance, which is chosen from the new horizon college English (2nd edition) issued by Foreign Language Teaching and Research in Beijing. It is a great educational article for those students who have a strong utilitarian psychology and an obvious materialistic tendency. The article has such a word: "Can't we educate people for life as well as for a career?" This problem is rather thought-provoking for every educator. Most of the time we maybe merely pay attention to one side but ignore the other in our CET practices. On many occasions, we only concentrate upon the interpretations of language knowledge itself and focus on the cultivation of language skills, but ignore the nurturing of students' comprehensive humanistic quality.

According to the syllabus requirements released by Chinese CET Committee (2007), the aim of English teaching in college is to cultivate students' general skills of using the language, especially listening and speaking abilities, and it can make students use English to communicate with others effectively in the future work and social activities, At the same time, it develops their ability of independent learning, and improves the comprehensive humanistic quality in order to let them adapt to the social development in our country. So when dealing with the English texts, teachers must bear the double undertakings of both imparting the linguistic knowledge of its own and influencing positively the students' intellectual or aesthetic sentiment.

\subsubsection{Discussion after the Class}

After finishing the text, teachers should organize some discussions or debates revolving around the central issues in each unit to reinforce students' understanding of the theme, heighten their ideological level and enhance their quality of humanities. Many a text in college English course book is filled with enterprising and positive contents which are concerned about life philosophy, secrets to success, the cultivation of personal character, outlook and values on outside world, scientific attitude toward ordinary phenomenon and so on and so forth.

Now let's exemplify this with another unit "American Dream" taken from College English Integrated Course 4 by SFLEP. When completing the text "Tony Trivisono's American Dream", teachers can question students "what quality elements help the persona to fulfill his dream?" for them to discuss among groups. By reflecting how the hero, an illiterate immigrant to USA from Italian rocky mountains, started from scratch but realized his ambition through hard struggle, students may intuitively conclude what features drive those to reach success: great vision, self-control, self-respect, optimism, determination and integrity. By means of such discussion the theme, students' souls get baptized unknowingly.

\section{Juxtapose the Quality-Oriented Education and the Tool-Driven Teaching in CET}

Guided by the scientific development concept, all English teachers should explore the road of reform and improve the teaching methods in order to juxtapose the quality-oriented education and the instrument-driven teaching in CET practices. They should treat cultivating and developing students' quality as the standpoint of CET, which functions as an effective platform to guarantee the implementation of quality education. The combination of quality-oriented education with the instrument-driven teaching in CET should adopt the following principles:

\subsection{People-Oriented Educations}

The people-oriented English quality education can be classified into two aspects of teachers and students. To improve quality education, teachers must heighten their own comprehensive qualities at first because the key of 
quality education mode lies in teachers' quality. Teachers need to make use of the teaching material creatively and let the quality education penetrate the whole process of CET; at the same time, teachers must also study the teaching material intensively, especially pay attention to their teaching methods. In a word, the higher teachers' qualities are, the stronger their abilities are, and the more flexible and diversified their teaching methods become. Then teachers exert enormously beneficial influence in cultivating and developing the students' qualities during the course of teaching. The core of scientific development concept is "people-oriented". Implemented in English teaching; it can be called student-oriented. All school managements should serve for students; all the school performances should focus on students and English teachers should regard students as the main part of CET.

\subsection{Better Methods}

Teaching methods and means are the main factors in implementing quality education. The quality education actually aims to boost the students' comprehensive ability, so the core of the CET quality education is to cultivate and improve the students' integrated ability in applying English skills and in upgrading their own qualities. English teachers should discard the old teaching ideas, break the bondage of examination, and truly let quality education which intends to improve the students' synthetic ability enter the CET practices. With the implementation of quality education, the teaching methods should be refined step by step in that the teaching methods are directly correlated with students' learning; therefore, centering around developing the students' whole quality, teachers should carefully design all aspects of the teaching process beforehand and they should try to use heterogeneously workable teaching methods in the classroom.

\subsection{Reasonable Teaching}

Generally speaking, CET in most Chinese universities set up listening speaking course, integrated English course, etc. but how to carry out the effective and reasonable teaching in a large class is also the major problem of CET now. The goal of English teaching is to improve the abilities of students' listening, speaking, reading, writing, translating and grammar; the process of English teaching must take every aspect into account. Student's English level is extremely uneven in a class that usually contains more than 60 students, so teachers need to communicate more with students via chatting, testing and other forms of interactions to understand the students' learning needs and make clear their mastery degrees of what have been taught. Then, in view of the level of whole class, teachers can arrange the teaching materials reasonably and make the abilities of student s' listening, speaking, reading, writing, translating, and grammar get developed harmoniously. In the meantime, teachers can optimize their teaching arrangements to conduct the quality education based on the analysis of students' learning styles, professional orientations and personal interests etc.

\subsection{Sustainable Teaching}

To meet the high social criteria for students' practical application ability for foreign language, we'd better enforce four years of CET continuously. Due to the limitation of the current teaching resources, many colleges only establish CET courses for the freshman and sophomore; however, it goes against the English quality education completely. Therefore, the relevant university administrations must take appropriate measures to make some reforms with the purpose of resolving the existing problems in CET practices. In the first two years, some Basic English Courses can be opened to reinforce students' primary abilities of listening, reading, speaking, writing, translating and grammar; and some optional English courses such as British \&American literature, cross-culture communication, linguistics, business English or other major-related ESP courses are provided for juniors and seniors to select freely in the light of their individual career plan or learning needs. Thus doing, the four years sustainable CET provides an effective guarantee to promote the overall level of quality-centered and instrument-oriented English education.

\section{Conclusion}

Nowadays, English is defined as "the important carrier of modern information, a bridge to the world". Obviously English tends to serve as a tool for most Chinese. But the ultimate aim of English Teaching is to develop humanistic qualities as well. Tool-oriented teaching and quality-centered education are not contradictory to each other; tool-oriented teaching is also a part of humanistic quality education. From the perspective of humanistic education, students can clearly know more about instrumental functions of English language, and then they can find more effective means to use English as a tool.

On the other hand, humanistic quality education cannot be separated from the language instrumental teaching. Although college English texts contain rich and colorful humanism, such humanity qualities as" emotion, attitude, values" are not formed naturally. If students look at the humanistic content as a split part independent from language learning, quality education in CET will become an empty talk. Noticeably, in specific teaching 
practice, some teachers will mechanically make teaching activities cut into two distinct parts on the ground of instrumental features; students do language training in the first period of class and enhance humanistic or ideological quality in the second half. In truth, cognition and emotion are intimately intertwined. That is to say, every aspect of English teaching is not always purely instrumental and excludes the cultivation of humanistic quality, and vice versa.

English, a commonly-used language tool and CET, a basic course in university, are both filled with abundant humanistic qualities. The long-term purpose of CET is to develop students' language skills in practical application and to cultivate students' temperament and to enhance their humanities, which should not be isolated but be integrated.

\section{References}

Cai Jigang. (2010). FLT in the age of globalization: Developing humanistic qualities or serving as a tool. Journal of Foreign Languages, 33(6), 33-40.

Cheng Zhenquan. (2008). The unity of instrumentalism and humanism-some thoughts on college English curriculum. Shandong Foreign Language Teaching Journal, 126(5), 9-12.

Cook, V. (2007). The goal of EFL: Reproducing native speakers or promoting multi-competence among second language users?

Cummins, J., \& C. Davision. International Handbook of English Language Teaching. New York: Springer.

Dai Weidong. (2001). The construction of the streamline ELT in China. Foreign Language Teaching and Research, 33(5), 323-327.

Higher education department of China education ministry. (2007). College English curriculum requirements. Shanghai: Shanghai Foreign Language Education Press.

Lan Renzhe. (2009). Rethinking the ideology of English language education in schools. Foreign Language in China, 32(6), 4-16.

Liu Runqing (2003). Reflections on the foreign language teaching. Research in Foreign Language and Literature, $3(1), 44-49$.

Liu Runqing. (2004). On the reform of college English teaching in China. CELEA Journal, 27(4), 3-8.

Luo Yimin. (2002). The negative effects and countermeasures of the instrumental theory in foreign language education. Foreign Languages and Their Teaching, 156(3), 50-51.

Yang Zijian. (2004). on the reform of foreign language education. Foreign Language in China, 1(1), 14-16. 